\title{
Mystery Calling Research in the Frontline of Higher Education
}

\author{
Jäckel, Katalin ${ }^{1}$ Heitler Lehoczky, Mária ${ }^{2}$ \\ ${ }^{1}$ jaeckel.katalin@kkfk.bgf.hu, Assistant professor \\ ${ }^{2}$ maria.lehoczky@gmail.com, Senior lecturer \\ Budapest Business School, Faculty of International Management and Business,22-24 \\ Diósy Lajos street, Budapest, Hungary
}

\begin{abstract}
There is a strong relationship between buyers' perceived risk and their satisfaction in out-of-standard situations of services. The customer-specific feature of these situations has been modelled as jaycustomers, i.e. customers of nonstandard behaviour. In education - due to students' expectations - the control of different situations is of high importance. The purpose of our research is to study administrative staff's behaviour when they find themselves face-to-face with so called 'jaystudents'. To solve the problem of research, an interdisciplinary approach of psychology and marketing is needed.

As far as methodology is concerned a basically qualitative experimental design has been selected with some quantifiable elements. The research process starts with a series of mystery callings followed by post-experimental focus group discussions. In service research mystery calling is usually applied for testing standards. As a new methodological approach of our research, the application of experimental techniques in exceptional service frontline situations can be mentioned.

From managerial aspects the results can provide the management with realistic information on the weaknesses of frontline personnel and of frontline standards. They can serve to improve human resource management in higher education. Based on the results we are
\end{abstract}

going to extend the investigations to faceto-face contexts.

Keywords: higher education, jaystudent, experimental research

\section{The objective of the research}

The risks of the users perceived in the extraordinary situations of providing services are strongly related to the stability of quality. The consumer-specific nature of the situations is modelled by the typology of services marketing as jaycustomer, i.e. the consumers of non-standard behaviour. In the perceived standard of quality parameters that are regarded important by the institution communication between the students and the representatives of the institution is decisive as attitude is expressed there and in this way it can be examined. In higher education quality management administration is of primary importance as routine tasks are mainly acted out there.

The objective of our research is to compare the perceived behaviour with the expected behaviour patterns from the part of the front-line administrative staff in the case of different 'jaystudent' behaviour at phone encounters. Solving the research problem requires both marketing and psychological approaches. 
1.1. The stages of the research Mystery calling research

The research is based on standardised questionnaires, in 62 simulated cases with the participation of 15 researchers on the administrative staff of different higher education institutions of business studies.

\section{Defining simulation}

The volunteering students had to turn to one of the colleagues of the administrative staff with a problem made up by having chosen one of the predefined jaystudent forms of behaviour in the form of mystery calling to the higher education institution selected. The interaction was evaluated on the basis of the points of view formed during focus group discussions in the form of an observation sheet distributed beforehand.

Dealing with matters on the phone was selected for several reasons. The respondents marked dealing with matters on the phone as one of the areas to be improved during the focus group discussions. Communication restricted to the vocal channel helps students in acting out a role as fewer paraphernalia of acting are necessary than in the case of direct, face to face interaction.

\subsection{The results of Mystery Calling research}

Researchers (15) acted out all jaystudent types (violators, doubters, grabbersexigents, arguers, idea originators, agitators) during the research in 62 cases in total. Two colleges and two universities were contacted in different situations. In most cases the Office of the Registrar, Marketing Department, Department of Foreign Languages and Methodology were called.

The situations were the following: calling off an application to an exam, asking for information, the sum of the tuition fee to be paid during internship, and also contacts were made to ask about acknowledging credits, student grants, internship, optional subjects, dropping a subject, exam results etc. The descriptive statistics of the answers is the following:

How many calls were unsuccessful? $35 \%$.

How many times did it ring? 80\% 3-5 rings

Did the front-line staff introduce themselves? $82 \%$ No.

Did they identify the student (in the case of a personal problem? $95 \%$ No

In what percentage was the problem solved? $22 \%$ solved in $100 \%$

Were they transferred to somebody else said to be more competent? $34 \%$ Yes

Structured list of behaviour forms to examine front-line staff

The behaviour of the administrative staff targeted was evaluated as follows (Q: Please evaluate the behaviour of the front-line staff following the conversation on a four-point scale. 1 means dissatisfaction while 4 expresses satisfaction.):

We can stress that clarity and loyalty to the institution were given the highest number of points when communication style was evaluated. When it comes to examining sensitivity to the problem the best result was given to listening to the problem and the worst to examining the problem by means of further questions. In the case of problem solving nearly similar values were assigned and answers are spread to the greatest extent here. Regarding decision making ability on the list of behaviour forms the weakest link is bearing responsibility from the administrators' part as respondents stated. Relatively similar values were assigned to the questions on frustration tolerance, as well. 


\begin{tabular}{|c|c|c|}
\hline Style of communication: & average & Std. dev \\
\hline friendly: creates an intimate relationship, congruent & 2.79 & 1.14 \\
\hline $\begin{array}{l}\text { courteous: deals with the student with respect following the social stan- } \\
\text { dards }\end{array}$ & 3.07 & 0.95 \\
\hline clarity: clear what they say, well articulated & 3.44 & 0.67 \\
\hline $\begin{array}{l}\text { ready to help: takes care, deals with the student as a peer, does not expect } \\
\text { them to be well informed in academic matters }\end{array}$ & 3.05 & 1.09 \\
\hline ironic: (evaluation: 1.formal 4. ironic) & 1.45 & 0.81 \\
\hline loyalty to institution: (evaluation: 1 not loyal 4 loyal) & 3.41 & 0.85 \\
\hline \multicolumn{3}{|l|}{ Sensitivity to problem: } \\
\hline $\begin{array}{l}\text { listens to the problem: the student can talk about the entire problem in } \\
\text { details }\end{array}$ & 3.43 & 0.76 \\
\hline asks for information: asks questions, asks for clarification & 2.36 & 1.12 \\
\hline $\begin{array}{l}\text { understands the problem: the problem is entirely or partly repeated, } \\
\text { checks if the partner is aware of it and asks for feedback }\end{array}$ & 2.45 & 1.11 \\
\hline $\begin{array}{l}\text { understands the situation: states the background and factors of arising } \\
\text { problems }\end{array}$ & 2.55 & 1.14 \\
\hline \multicolumn{3}{|l|}{ Problem solving ability: } \\
\hline well-informed: knows rules, possibilities, similar cases & 2.82 & 1.14 \\
\hline $\begin{array}{l}\text { suggests constructive, common brainstorming: makes and asks for sug- } \\
\text { gestions }\end{array}$ & 2.78 & 1.51 \\
\hline $\begin{array}{l}\text { explores interests: focuses on common interests, objectives by separating } \\
\text { the person from the problem }\end{array}$ & 2.76 & 1.10 \\
\hline $\begin{array}{l}\text { shows alternatives: considers the needs and the opportunities of the stu- } \\
\text { dent }\end{array}$ & 2.84 & 1.03 \\
\hline \multicolumn{3}{|l|}{ Decision making ability: } \\
\hline $\begin{array}{l}\text { argues for the best alternative: helps in selecting the most favourable so- } \\
\text { lution }\end{array}$ & 2.82 & 1.07 \\
\hline suggests an action plan: the selected solution is broken down into steps & 2.72 & 1.11 \\
\hline $\begin{array}{l}\text { bears responsibility: shows personal attachment, suggests further contact } \\
\text { in problem solving }\end{array}$ & 1.80 & 0.94 \\
\hline directs communication: gets back to the point & 2.97 & 0.91 \\
\hline \multicolumn{3}{|l|}{ Frustration tolerance: } \\
\hline $\begin{array}{l}\text { reacts with cold blood: patient, balanced, calm and does not allow to be } \\
\text { provoked emotionally }\end{array}$ & 3.11 & 1.02 \\
\hline $\begin{array}{l}\text { empathy: understands the extreme feelings of the students and calms } \\
\text { them down, does not them off or despise them }\end{array}$ & 2.87 & 1.12 \\
\hline realises and analyses the conflict: deals with the student as a peer & 2.98 & 0.96 \\
\hline firm: not aggressive and not subordinate & 3.05 & 0.90 \\
\hline
\end{tabular}

\section{What else did you expect from the em- ployee of the institution?}

Who were not satisfied with the services provided would have expected the following:

'showing interest and a positive attitude', 'not telling off rather giving information', 'if he does not know the answer offer to find it out and inform later', 'a normal tone', 'readiness to help', 'sug- gestions about what to do', 'greater preparedness'.

This style is "Body Text," which we use for second and subsequent paragraphs. The following is an example of the "Bullet" style, which you may want to use for lists.

We can stress that clarity and loyalty to the institution were given the highest number of points when communication style was evaluated. When it comes to 
examining sensitivity to the problem the best result was given to listening to the problem and the worst to examining the problem by means of further questions. In the case of problem solving nearly similar values were assigned and answers are spread to the greatest extent here. Regarding decision making ability on the list of behaviour forms the weakest link is bearing responsibility from the administrators' part as respondents stated. Relatively similar values were assigned to the questions on frustration tolerance, as well.

What else did you expect from the employee of the institution?

Who were not satisfied with the services provided would have expected the following:

'showing interest and a positive attitude', 'not telling off rather giving information', 'if he does not know the answer offer to find it out and inform later', 'a normal tone', 'readiness to help', 'suggestions about what to do', 'greater preparedness'.

This style is "Body Text," which we use for second and subsequent paragraphs. The following is an example of the "Bullet" style, which you may want to use for lists.

\subsection{Summary}

On the basis of the results of mystery calling the areas that must be improved by all means can be identified. In the exploratory research students complained that the administration is difficult to be contacted, which did not show up markedly in the present research results. Another problem is that when answering the phone the employees of the administrative department do not name either the institution or themselves and only a few of them identify the student. (However, to tell the truth highly confidential situations affecting privacy were not simulated during the research).

In contrast with the qualitative research results and those of the preliminary questionnaires the present results did not justify the problem of the students, namely, that the departments and the Office of the Registrar plays 'table tennis' with the students by referring them to the authority of others. Another positive result is that there were very few conflicts although this can be due to simulating the experiment. The motivation of the student was not the solution of the problem, rather, the proper way of conducting the research, which can be seen as a moderating factor by all means.

\subsection{Practical applicability}

The objective is to prepare front-line staff for managing all different types of jaycustomers, stabilise the quality and standard of the work of the front-line staff by continuously monitoring them as well as improve their performance at all time. According to the opinions, criticism and expectations the task of the service provider is to make the front-line processes more perfect. Nevertheless, the objective of our research was not the evaluation of the single front-line staff, rather the exploration of the possible forms of behaviour in non-standard situations.

The results can be applied in practice e.g. in the quality management of higher education on the one hand. On the other hand, they can serve as a basis for further research on front-line based services. Moreover, as a by-product of the research new points of view in the human resource management of services when selecting and controlling front-line staff are also provided. This research will be practically applicable because it can help to develop proactive provider behaviour. If conflicts are defined in an inappropriate manner, it may cause further conflicts. 
Exploring conflicts will make it possible to focus quality development procedure there where defects occur.

\section{References}

[1] Fisk, R.- Grove S.- Harris, L.C.Keeffe, D.A.- Daunt, K.L.- RusselBennett, R.- Wirtz, J.(2010): Customers behaving badly: a state of the art review, research agenda and implications for practitioners Journal of Marketing, Vol.24. Iss:6 pp. 417-429.

[2] Jäckel, K. (2010): Frontline audit in higher education - Exploring conflict situations in higher education), $\mathrm{PhD}$. Thesis, BGF KKK.

[3] Lovelock, Ch. - Wright, L. (2007): Services Marketing, People, Technology, Strategy,(sixth edition) Pearson Prentice Hall, Upper Saddle River, New Jersey

[4] Veres, Z. (2009): Foundations of Services Marketing, Akadémiai Kiadó, Budapest

[5] Wirtz, J. (2008): Future Research Opportunities Related to Jaycustomer Behavior, AMA SERVSIG International Research Conference 2008, Liverpool, UK. 